\title{
Las relaciones económicas entre Angola y China (2000-2014)
}

\author{
Economic Relations between \\ Angola and China (2000-2014)
}

\author{
HELTON RICARDO OURIQUES* \\ AMANDA CAROLINE NUNES DE AVELAR*
}

Resumen: El objetivo es analizar las relaciones entre China y Angola desde principios de la década de 2000 con el fin de demostrar que la profundización de las relaciones económicas la determina el contexto de la economía política china, lo que ha implicado la búsqueda de los recursos estratégicos necesarios para mantener su modelo de crecimiento. Se pretende saber si este mayor acercamiento es o será capaz de modificar la posición periférica angolana en la economía global, y se concluye que esta circunstancia no es condición suficiente para un cambio estructural de su ubicación en la economía-mundo capitalista.

Palabras clave: petróleo; relaciones económicas; economía política internacional.

Abstract: The aim is to discuss economic relations between China and Angola since the 2000s to demonstrate that economic ties between the two countries have deepened in the changing context of Chinese political economy, which has resulted in a search for strategic resources in order to maintain it's model of economic growth. We attempt to understand whether this increased economic rapprochement can change the Angolan peripheral position in the global economy; we

Recepción: 14 de abril de 2015. / Aceptación: 13 de octubre de 2016.

* Universidad Federal de Santa Catarina, Brasil, helton.ricardo@ufsc.br / amanda.avelar@gmail.com 
conclude that the current situation does not represent sufficient conditions for a structural change in the position of Angola in the capitalist world-economy.

Key words: petroleum; economic relations; international political economy.

\section{Introducción}

Como se argumentó en otro trabajo, ${ }^{1}$ desde la fundación de la República Popular China, en 1949, el país ha adoptado en su política exterior un enfoque de acercamiento a las naciones africanas, principalmente por razones políticas. El momento decisivo ocurrió en la Conferencia de Bandung, en 1955, en la que asiáticos y africanos crearon el Movimiento de Países no Alineados, cuyo objetivo era mantenerse neutrales y no aliarse con la Unión Soviética ni con Estados Unidos. Por la situación interna de China (proceso de reforma y apertura), durante los primeros años de la década de 1980 los lazos con África se debilitaron, pero a partir de la década de 1990, China volcó su atención en los países del Tercer Mundo. Fue simbólica la visita del presidente Jiang Zemin a África, en 1996, ${ }^{2}$ en la que presentó una propuesta de cinco puntos ${ }^{3}$ cuya intención era establecer los términos de una nueva relación con esta región. Así, África se convirtió en un foco importante en la política de "asociación estratégica” china y, desde entonces, la diplomacia se ha esforzado por fortalecer sus vínculos con los países africanos y por construir no sólo acuerdos económicos y comerciales, sino también cooperación técnica, política y militar.

Algunos autores ${ }^{4}$ sugieren que esto se debe a la necesidad de China de una mayor participación en el comercio internacional,

${ }^{1}$ Helton Ricardo Ouriques, “As relações econômicas entre China e África: uma perspectiva sistêmica”, Carta Internacional, vol. 9, núm. 1, enero-junio de 2014, pp. 1943.

${ }^{2}$ Chris Alden, "China in Africa", Survival: Global Politics and Strategy, vol. 47, núm. 3, 2005, pp. 147-164.

${ }^{3}$ Los cinco puntos serían los siguientes: la notable amistad, la igualdad soberana, la no intervención, el beneficio mutuo y la cooperación para el desarrollo.

${ }^{4}$ Para detalles, véase: Diego Pautasso, “A economia política internacional da China para Angola e os caminhos da transação sistêmica”, Século XXI, vol. 1, núm. 1, enero-di- 
pues su propósito es mantener el rápido ritmo de crecimiento económico. La razón es que, debido a la mayor capacidad de exportación y el fortalecimiento del mercado interno, ha aumentado la demanda de mercados y materias primas y, por lo tanto, se ha fortalecido el peso político y diplomático del país en el contexto global, lo que lo obliga a replantear su posición geopolítica y formar nuevas alianzas.

El interés de China en África debe verse, entonces, como resultado de este reposicionamiento estratégico, en vista de las exigencias de productos naturales que apoyen su modelo de desarrollo. ${ }^{5}$ El tamaño de la población, la disponibilidad limitada de tierras cultivables y la demanda de energía son ejemplos que explican la urgencia china de recursos que abundan en África y que son indispensables para el modelo de crecimiento de su economía, basada en la expansión de la industria pesada, los bienes raíces y la infraestructura, y en el aumento de la producción propia y el consumo interno de productos manufacturados, como los automóviles.

Las inversiones chinas en África aumentaron de casi $500 \mathrm{mi}$ llones de dólares en 2003, a 22.9 millares de millones en 2012 . $^{6}$ Además, más de 2000 empresas chinas comenzaron a invertir en la región, especialmente en minería, finanzas, industria, construcción y agricultura. Es evidente que, sin embargo, el mayor interés de China en el corto y mediano plazos está vinculado a la disponibilidad de fuentes de energía, especialmente el petróleo. No es de extrañar, por lo tanto, que los países productores de petróleo de la región, como Angola, Nigeria y Libia, sean algunos de sus principales socios comerciales. En 2012, África representó 10.9\% de la producción de petróleo del

ciembre de 2012, pp. 106-127, y Padraig Carmody y Francis Owusu, “A expansão da China para a África: interesses e estratégias”, en Rodrigo Pimentel Ferreira Leão, Eduardo Costa Pinto y Luciana Acioly (comps.), A China na nova configuração global: impactos políticos e econômicos, Brasilia, Instituto de Pesquisa Econômica Aplicada, 2011, pp. 235-267.

${ }^{5}$ En este contexto, el estudio de Baban Hasnat, "The US and Chinese Foreign Direct Investment in Africa”, China-USA Business Review, vol. 12, núm. 8, 2013, pp. 735-745, al comparar las inversiones de Estados Unidos y China en África en los últimos años, muestra que la motivación de estos dos países es la misma: el acceso y control sobre los recursos naturales.

${ }^{6}$ The China Analyst, "Hong Kong”, Hong Kong, The Beijing Axis, 2013. 
mundo. ${ }^{7}$ Según esta fuente, Angola aportó 2.1\% de la oferta de petróleo mundial, mientras que Nigeria ofreció $2.8 \%$, y Libia, $1.7 \%$. Es importante resaltar que China, aunque es el mayor consumidor de petróleo $(11.7 \%$ del que se consumió en el mundo en 2012), cuenta con pocos hidrocarburos y una oferta insuficiente para satisfacer su demanda interna (apenas produjo 5\% del total de petróleo en el mundo en 2012). Por ello, pragmáticamente ha estrechado sus relaciones económicas con estos países africanos, como una manera de diversificar sus fuentes de suministro (en vista de la inestabilidad en Medio Oriente, la principal región productora) y asegurar, a largo plazo, el combustible que sustente su crecimiento económico.

La mayor presencia de China en África, a través de inversión directa, se contextualiza en una estrategia más general de internacionalización de su economía; en otras palabras, surge en el proceso de expansión de la inversión china en todas las regiones del mundo, según el modelo Go Global. Cuando se habla de África, se debe recordar que no es la mayor receptora de los flujos de inversión de China, y que estas inversiones se concentran en pocos países de ese continente. ${ }^{8}$

De cara a su situación interna, China ha dirigido su atención a África con más fuerza a partir de la década de 2000, lo que ha afectado el crecimiento económico de algunos países de esa región que, como muchos en América Latina, entraron en la fase del "auge de las materias primas"; es decir, el aumento real de los precios de estos productos básicos, impulsado por una mayor demanda de China, fue el motor de la expansión económica de ambas regiones periféricas. En el caso de África, diversos autores ${ }^{9}$ señalan que gran parte del crecimiento económico se debe al estrechamiento de las relaciones con China. El

${ }^{7}$ British Petroleum, Statistical Review of World Energy 2013, Londres, 2013.

${ }^{8}$ Para detalles, véase: Katarina Koblinski, Chinese Investment in Africa: Checking the Facts and Figures, Briefing Paper 7, Association for International Affairs, julio de 2012; y Mary-Françoise Renard, China's Trade and FDI in Africa, Working Paper 126, Túnez, African Development Bank Group, 2011.

${ }^{9}$ Para detalles, véase: Carmody y Owusu, "A expansão da China para a África: interesses e estratégias", op. cit.; Pautasso, "A economia política internacional da China para Angola...", op. cit., y Felix Edoho, "Globalization and Marginalization of Africa: Contextualization of China-Africa Relations”, Africa Today, vol. 58, núm. 1, 2011, pp. 102-124. 
Fondo Monetario Internacional reveló que, a partir de la década de 2000, el África subsahariana tiene el segundo mayor incremento del producto interno bruto, sólo superada por Asia (incluida China) en términos de crecimiento.

El desarrollo económico de África se produjo a partir del aumento de las exportaciones de la región; sin embargo, en comparación con el total de la economía mundial, el movimiento de la década de 2000 sólo consiguió recuperar el terreno perdido durante las décadas de 1980 y 1990. Después de todo, la participación de África en el valor de las exportaciones mundiales, que fue de $5.92 \%$ en 1980, llegó a 3.42\% en 2012. Muy diferente parece ser la trayectoria de Asia en general, y de China en particular, que aumentó significativamente las exportaciones en relación con la cantidad global. Aun así, países como Angola tuvieron un importante crecimiento económico en la última década, en gran parte determinado por la demanda china.

Sin embargo, si se reflexiona sobre la perspectiva teórica del análisis del sistema mundial, es necesario separar situaciones coyunturales de la posición estructural. Immanuel Wallerstein sostiene que el capitalismo histórico es desigual y polarizado. ${ }^{10}$ Giovanni Arrighi, por su parte, argumenta que hay posiciones estructurales de centro, semiperiferia y periferia en el sistema interestatal. ${ }^{11} \mathrm{La}$ cuestión es si la mayor cercanía económica entre Angola y China de los últimos años es o será capaz de cambiar la posición periférica angoleña en la economía global. Para ello, se presenta un marco general de las relaciones entre Angola y China, luego se analiza con detalle el papel central del petróleo en estas relaciones, se muestra la importancia de China en Angola y se hacen reflexiones de carácter más general y teórico al respecto. En las consideraciones finales se muestra que esta relación económica es circunstancialmente beneficiosa para ambos países, pero que no es condición suficiente para un cambio estructural de la posición periférica de Angola en la economía-mundo capitalista.

\footnotetext{
${ }^{10}$ Immanuel Wallerstein, Capitalismo histórico e civilização capitalista, San Pablo, Contraponto, 2001, pp. 118-119.

${ }^{11}$ Giovanni Arrighi, A ilusão do desenvolvimento, Petrópolis, Vozes, 1997, pp. $150-160$.
} 


\section{Las relaciones económicas entre Angola y China}

De todo el petróleo importado por China, más de $20 \%$ proviene de África, según cifras de la base de datos Comtrade. ${ }^{12} \mathrm{La}$ mayor parte de estas importaciones se origina en Angola, que, desde la primera década de este siglo, ha figurado como un importante proveedor sólo superado por Arabia Saudí.

En este escenario, Angola se erige como el principal socio estratégico entre los países africanos, puesto que es también uno de los destinos privilegiados de la inversión directa de China, cuya presencia en este país africano está enfocada a la reconstrucción de la infraestructura, ampliamente devastada durante la guerra civil, que se extendió de 1975 a 2002.

Los precios de los productos básicos, así como de otros bienes que circulan en las redes internacionales de comercio, experimentan un cambio constante, fuertemente relacionado con uno o más factores, a saber: el contexto histórico mundial, el comportamiento del mercado internacional de mercancías (regido por las leyes de la oferta y la demanda), el crecimiento o las crisis económicas y los fenómenos meteorológicos, entre otros.

Durante el siglo xx, las materias primas agrícolas e industriales sufrieron una caída en sus precios internacionales en relación con los productos manufacturados, principalmente debido a la innovación tecnológica en el campo y la industria. Según Clarissa Black, ocurrió una reducción en los costos de producción de los productos agrícolas causada por la mecanización, así como por el incremento del uso de fertilizantes. ${ }^{13}$ $\mathrm{Y}$, para la industria, el consumo de materias primas - especialmente de acero, hierro y cobre- tuvo una ligera reducción por el aumento de precios y la mayor utilización de las tecnologías de la información en los procesos productivos.

Durante la década de 1970, sin embargo, las dos crisis del petróleo y la devaluación del dólar provocaron un aumento re-

${ }^{12}$ La Commodity Trade Statistics Database (Comtrade) de las Naciones Unidas es una plataforma donde están los datos detallados sobre las importaciones y exportaciones de alrededor de 200 países de todo el mundo.

${ }^{13}$ Clarissa Black, "Eventos relacionados ao superciclo de preços das commodities no Século XXI”, Indicadores Econômicos, vol. 40, núm. 2, 2013, pp. 67-78. 
lativo de los precios de los productos tanto agrícolas como industriales. La naturaleza de la relación entre los precios del petróleo y las materias primas se define por el aumento de los costos de transporte, fertilizantes y procesos industriales que utilizan el petróleo como materia prima. A partir de esa fecha empezó un nuevo periodo de oscilación de los precios de las materias primas, con una baja en la década de 1990 y una alza a principios de los años 2000; sin embargo, a diferencia de los altos precios registrados en décadas anteriores, la subida de los precios de las materias primas en el siglo XXI se atribuyó a los desequilibrios entre la oferta y la demanda, al aumento de los precios del petróleo, al crecimiento económico global, al "efecto China", a cambios climáticos, etcétera.

Daniela Prates ${ }^{14}$ cita, además, otros factores específicos o de corto plazo que contribuyeron a la subida de los precios de determinados grupos de productos básicos: la reducción de la oferta provocada por el aumento de los costos de producción y el aumento de los precios del petróleo, que, como se dijo, dispararon los precios de ciertos productos básicos y los costos de transporte.

Clarissa Black, ${ }^{15}$ a su vez, apoya la importancia de las razones ponderadas por Prates, pero sostiene que no debe subestimarse el alza de los precios del petróleo - provocada por cuestiones geopolíticas y el aumento de los costos de producción de la industria-, ni la devaluación del dólar y las bajas tasas de interés. La debilidad del dólar pone en desventaja a las empresas y los países exportadores de petróleo y de otras materias primas, y éstos se anticipan a las pérdidas aumentando sus precios. Por otro lado, las bajas tasas de interés alientan el mercado financiero de materias primas, ya que los bonos del gobierno se hacen menos atractivos.

Thomas Helbling, Valerie Mercer-Blackman y Kevin Cheng ${ }^{16}$ añaden que las economías emergentes -China, India y otros países de Medio Oriente-impulsaron la demanda de ma-

${ }^{14}$ Daniela M. Prates, "A alta recente dos preços das commodities”, Revista de Economia e Política, vol. 27, núm. 3, 2007, pp. 323-344.

${ }^{15}$ Black, "Eventos relacionados...", op. cit., p. 70

${ }^{16}$ Thomas Helbling, Valerie Mercer-Blackman y Kevin Cheng, "Commodities Boom: Riding a Wave”, Finance and Development, vol. 45, núm. 1, marzo de 2008, p. 14. 
terias primas debido al crecimiento de la población y del ingreso. El último factor también es responsable del cambio en los hábitos de consumo de estos consumidores, que incluyen en su dieta alimentos ricos en proteínas, como carne, productos lácteos, cereales, mariscos, aceites, frutas y verduras. El principal efecto de esta secuencia de eventos es, según estos autores, una mayor ganancia para los exportadores de productos básicos y los países petroleros, cuyos saldos del comercio se ven favorecidos en relación con los países que importan esos bienes.

Por lo tanto, como las actividades económicas de un grupo de países emergentes giran en torno a la exportación de petróleo y materias primas, los autores afirman que el aumento de los precios de los productos es, en gran parte, responsable del crecimiento experimentado en los últimos años por estas economías. Es en este escenario donde deben entenderse los resultados económicos de Angola en la última década.

Abundante en recursos naturales, la economía de Angola se basaba, hasta la segunda mitad del siglo pasado, principalmente en la producción agrícola. Según un informe del Banco Mundial, “antes de la independencia, Angola era más conocida como exportadora de café que como exportadora de petróleo. Angola no sólo era el cuarto exportador mundial de café, sino que también exportó más de 400000 toneladas de maíz al año, por lo que se había tornado en uno de los mayores exportadores de alimentos de África subsahariana". ${ }^{17}$

El descubrimiento de petróleo en la década de 1950 transformó el marco económico del país, que actualmente depende en $80 \%$, en promedio, de la producción y el comercio de este recurso. El sector industrial constituye $65 \%$ del PIB, ${ }^{18}$ aproximadamente, mientras que el sector de los servicios y la agricultura representan 25 y 10\% del PIB respectivamente. Por otro lado, la actividad de extracción y comercialización de diamantes contribuye con 5\% del PIB; sin embargo, el petróleo y las actividades relacionadas, por sí solas, reportan $80 \%$ del PIB. Actualmente, Angola es el segundo mayor productor de petróleo de África;

\footnotetext{
${ }^{17}$ World Bank, Angola-Oil, Broad-Based Growth, and Equity, Washington, World Bank, 2006, p. 21.

${ }^{18}$ Sherelle Jacobs, “Angola: Rise of a New African Superpower”, African Business, núm. 387, junio de 2012, pp. 48-63.
} 
después de la independencia, la actividad petrolera se ha convertido en la más importante del país. ${ }^{19}$

Así pues, el incremento de los precios de los productos básicos, y sobre todo la subida del precio del barril de petróleo, fue esencial en el crecimiento económico de Angola en los últimos años. El cuadro 1, construido con la base de datos Comtrade, ilustra la evolución del PIB de Angola de 1996 a 2013 y los ingresos por exportaciones de petróleo crudo en el mismo periodo.

El análisis del cuadro 1 permite inferir que la exportación de petróleo crudo fue clave en la evolución del PIB en el periodo destacado; sin duda, el importante crecimiento experimentado desde la década de 2000 se debió principalmente a la contribución del sector petrolero a la economía.

Esta estrecha relación la describe Sherelle Jacobs en un artículo de African Business:

Sin embargo, las desventajas de la dependencia del país de los ingresos por exportaciones petroleras se hicieron evidentes durante la crisis mundial de 2008-2009, cuando la caída de la demanda de petróleo de los países consumidores llevó a que su precio promedio cayera a 56.15 dólares por barril (ajustado por inflación); por lo tanto, el crecimiento del PIB se desplomó en Angola, y cayó a 2.4\% en 2009 y a $2.3 \%$ en 2010. ${ }^{20}$

La caída puede ser dimensionada en comparación con el crecimiento del PIB de $13.8 \%$ en 2008 .

Aunque la pauta exportadora angoleña no está compuesta sólo por el comercio de petróleo crudo, refinados y sus derivados, es este sector el que estimula la economía en términos de crecimiento, ya que no presenta gran diversificación. Es decir, Angola se ha vuelto extremadamente dependiente de los hidrocarburos, y las fluctuaciones en los precios del petróleo

${ }^{19}$ En 1996, 95.18\% de las exportaciones angoleñas eran de petróleo crudo, y en 2012 este porcentaje ascendió a 98\%, según datos del Observatorio de la Complejidad Económica (A. J. Simoes y C. A. Hidalgo, The Economic Complexity Observatory: An Analytical Tool for Understanding the Dynamics of Economic Development. Workshops at The Twenty-Fifth AAAI Conference on Artificial Intelligence, 2011). Sin embargo, debe tenerse en cuenta la suma vendida: en 1996, las exportaciones de crudo fueron de alrededor de 3.35 millares de millones de dólares, y en 2012, de 46.3 millares de millones de dólares.

${ }^{20}$ Jacobs, “Angola: Rise of a New African Superpower”, op. cit., p. 51. 
CuAdro 1. Composición del PIB en comparación con los ingresos por exportaciones de petróleo en Angola, 1996-2013 (en millares de millones de dólares)

\begin{tabular}{lrcc}
\hline & \multicolumn{3}{c}{$\begin{array}{c}\text { Ingresos por } \\
\text { exportaciones } \\
\text { Año petróleo }(B)\end{array}$} \\
\hline 1996 & PIB $(A)$ & 4.22 & $5 / A$ \\
1997 & 7.53 & 4.19 & 54.77 \\
1998 & 7.65 & 2.95 & 45.74 \\
1999 & 6.45 & 3.76 & 61.14 \\
2000 & 6.15 & 7.89 & 86.42 \\
2001 & 9.13 & 5.97 & 66.78 \\
2002 & 8.94 & 7.2 & 47.09 \\
2003 & 15.29 & 8.8 & 49.41 \\
2004 & 17.81 & 12.33 & 52.36 \\
2005 & 23.55 & 20.94 & 56.64 \\
2006 & 36.97 & 30.67 & 58.55 \\
2007 & 52.38 & 38.34 & 58.74 \\
2008 & 65.27 & 65.4 & 73.86 \\
2009 & 88.54 & 37.65 & 51.46 \\
2010 & 73.16 & 39.4 & 47.26 \\
2011 & 83.37 & 63.15 & 56.95 \\
2012 & 110.89 & 70.23 & 55.96 \\
2013 & 125.49 & 67.29 & 48.63 \\
\hline
\end{tabular}

Fuente: Elaboración de los autores con datos de United Nations, U.N. Comtrade International Trade Statistics Database, Washington, y Banco Mundial, World DataBank, Washington.

o las crisis económicas, como la de 2008, afectan seriamente su crecimiento. Por otro lado, en un escenario económico internacional en el que la demanda de recursos naturales, especialmente de petróleo, es alta, las condiciones le son favorables. Es en este sentido, sobre todo, como se percibe en el país africano el "efecto China".

El escenario que se establece para Angola a principios del siglo XXI es el de una economía que necesita ser restaurada. Según el artículo citado de African Business:

Es difícil medir únicamente los efectos que la guerra tuvo en la economía angoleña. Llevó a 1.5 millones de muertes y dejó a más de cua- 
tro millones de ciudadanos refugiados internamente [...] Al usar su nueva herencia basada en el petróleo, Angola ha sido capaz de progresar espectacularmente en la reconstrucción de su infraestructura. Los resultados del boom de la construcción son evidentes en la polvorienta capital del país, Luanda, donde los rascacielos y las grúas adornan los cielos, y las hormigoneras se están volviendo tan comunes como los puestos callejeros. ${ }^{21}$

Pero más allá de Luanda y su modernización, la reconstrucción de Angola consiste en la rehabilitación de carreteras y ferrocarriles que cruzan el país y sus fronteras, así como de edificios públicos, hospitales y escuelas; y una renovación tanto de las redes de telecomunicaciones en las principales ciudades y en el resto del país, como de algunos sectores de la economía, entre otros.

Por otro lado, la economía china tuvo en las últimas dos décadas tasas de crecimiento elevadas y por encima de la media mundial, un factor que ha puesto en duda la posición de las economías occidentales en el ámbito internacional, como la de Estados Unidos. Sin embargo, asegurar la posición actual en las relaciones internacionales demanda mucho esfuerzo:

[...] la modernización de China ha creado las condiciones objetivas para la inserción internacional del país, para ampliar sus capacidades y necesidades económicas. Por supuesto, el ritmo de desarrollo económico de China ha dado importancia a la política de relaciones exteriores de China, con consecuencias obvias para la evolución del sistema internacional en el siglo xxi. ${ }^{22}$

Sin embargo, las relaciones bilaterales entre China y Angola no se iniciaron en las décadas de 1990 o 2000; ya en la de 1980 los dos países tenían intercambios turbulentos:

Del lado chino, la inserción internacional osciló entre la alianza con la URSS (1949-1962), el aislamiento (1962-1971), el acercamiento con Estados Unidos (1971-1989) y, finalmente, un comportamiento cada vez más autónomo (después de 1989). Del lado de Angola, la inserción internacional también sufrió choques relacionados con la lucha por la independencia (hasta 1975), la guerra civil (1975-2002) y, finalmente,

${ }^{21}$ Ibid., pp. 50-51.

${ }^{22}$ Pautasso, "A economia política internacional da China para Angola...”, op. cit., p. 109. 
la búsqueda de la estabilización y la reconstrucción. Debido a estas fluctuaciones, las relaciones entre China y Angola estuvieron marcadas por la inestabilidad y las tensiones hasta la década de $1980 .{ }^{23}$

De acuerdo con Diego Pautasso, las relaciones diplomáticas se remontan a 1983. Sin embargo, el primer acuerdo comercial se firmó al año siguiente, en 1984, cuando se creó una Comisión Económica y Comercial Común, que celebró su primera reunión apenas en 1999. Por lo tanto:

La independencia del país africano y la diplomacia pragmática lanzada por Deng Xiaoping en el contexto de la política de reforma y apertura de China sentó las bases del enfoque bilateral, pero fue sólo a finales del siglo xx cuando la relación ganó densidad. El documento diplomático Declaración Conjunta sobre el Establecimiento de Relaciones Diplomáticas entre la República Popular China y la República Popular de Angola (2002) selló el compromiso para intensificar las relaciones bilaterales. ${ }^{24}$

Desde entonces, Angola se convirtió en el país africano con más relaciones comerciales con China. En 2008, el comercio bilateral entre ambos alcanzó los 25.3 millares de millones de dólares; en 2012, según datos del Observatorio de la Complejidad Económica, Angola fue el país de África que más petróleo exportó a China, y hoy es, junto con Arabia Saudí, su mayor proveedor de petróleo. ${ }^{25}$

Las relaciones chino-angoleñas no se limitan al ámbito de las exportaciones y las importaciones. La presencia de China en Angola, así como en otros países africanos, está marcada por inversiones en diversos sectores, sobre todo en infraestructura. En palabras de Indira Campos y Alex Vines:

Con el final de la guerra en Angola, la reconstrucción rápidamente se convirtió en prioridad del gobierno. La República Popular China ha desempeñado, en particular, un papel importante en el apoyo a estos esfuerzos. Con la asistencia técnica y financiera de China se iniciaron más de 100 proyectos en las áreas de energía, agua, salud, educación, telecomunicaciones, pesca y obras públicas. Durante la visita del primer ministro chino, Wen Jiabao, a Angola, en junio de 2006, el presidente angoleño Eduardo dos Santos describió las relaciones bilaterales como

${ }^{23}$ Ibid., p. 111.

${ }^{24}$ Ibid., p. 113.

${ }^{25}$ Ibid., p. 112. 
una asociación "mutuamente beneficiosa", "pragmática", que no tiene "condiciones políticas". ${ }^{26}$

Así nació, en la primera década de este siglo, un "matrimonio de conveniencia” entre China y Angola, expresión usada por Lucy Corkin. ${ }^{27} \mathrm{El}$ crecimiento económico chino demanda recursos naturales fundamentales. La contraprestación por el suministro de petróleo a China significa para Angola la posibilidad de inversiones en el país.

Las relaciones económicas entre ambos países se intensificaron a partir de 2002. Durante la década de 1990, la suma de las importaciones y las exportaciones fluctuó en millones. En 2004, el volumen del comercio entre los dos países llegó a 4.7 millares de millones de dólares y, a partir de ese año, el volumen sólo creció, con una pequeña caída entre 2007 y 2008, durante la crisis económica mundial que se originó en el mercado estadounidense de bienes raíces.

El desarrollo del comercio entre los dos países puede observarse en el cuadro 2. En 2014 se comercializaron más de 37 millares de millones de dólares entre China y Angola, según los datos de la base de Comtrade:

No obstante, la relación comercial entre China y Angola no es equilibrada; el volumen importado por China ha sido mucho mayor que lo que este país ha exportado a Angola, por lo que la balanza comercial ha sido negativa para China. Como se observa en el cuadro 3, en el periodo 1992-2014, con excepción del año 1994, hubo un desequilibrio en la balanza comercial favorable a Angola, pero, a partir del 2000, el déficit de China aumentó de manera exponencial.

En 1992, por ejemplo, las exportaciones de China a Angola fueron de 8.4 millones de dólares, y las importaciones, de 29.4 millones de dólares. En 2004, estos valores alcanzaron 193 millones y 4.7 millares de millones de dólares respectivamente. Y en 2014 fueron 5.9 millares de millones los exportados de

\footnotetext{
${ }^{26}$ Indira Campos y Alex Vines, Angola and China: A Pragmatic Partnership, Londres, Center for Strategic \& International Studies, 2008, p. 1.

${ }^{27}$ Lucy Corkin, "China and Angola: Strategic Partnership or Marriage of Convenience?”, The Angola Brief, vol. 1, núm. 1, enero de 2011, p. 1.
} 
Cunadro 2. Desarrollo del comercio entre Angola y China, 1992-2014 (en millares de millones de dólares)

\begin{tabular}{lccc}
\hline & $\begin{array}{c}\text { Exportaciones } \\
\text { de Angola con } \\
\text { destino a China }\end{array}$ & $\begin{array}{c}\text { Importaciones } \\
\text { de Angola con } \\
\text { origen en China }\end{array}$ & Comercio total \\
\hline 1992 & 0.03 & 0.01 & 0.04 \\
1993 & 0.18 & 0.01 & 0.19 \\
1994 & 0.05 & 0.01 & 0.06 \\
1995 & 0.14 & 0.02 & 0.16 \\
1996 & 0.24 & 0.03 & 0.27 \\
1997 & 0.60 & 0.03 & 0.63 \\
1998 & 0.15 & 0.04 & 0.19 \\
1999 & 0.36 & 0.02 & 0.37 \\
2000 & 1.84 & 0.03 & 1.88 \\
2001 & 0.72 & 0.05 & 0.77 \\
2002 & 1.09 & 0.06 & 1.15 \\
2003 & 2.21 & 0.15 & 2.35 \\
2004 & 4.72 & 0.19 & 4.91 \\
2005 & 6.58 & 0.37 & 6.95 \\
2006 & 10.93 & 0.89 & 11.83 \\
2007 & 12.89 & 1.23 & 14.12 \\
2008 & 22.38 & 2.94 & 25.32 \\
2009 & 14.68 & 2.39 & 17.06 \\
2010 & 22.82 & 2.00 & 24.82 \\
2011 & 24.92 & 2.78 & 27.71 \\
2012 & 33.56 & 4.04 & 37.60 \\
2013 & 31.97 & 3.96 & 37.08 \\
2014 & 31.11 & 5.98 & \\
\hline & & &
\end{tabular}

Fuente: Elaboración de los autores con datos de United Nations, U.N. Comtrade International Trade Statistics Database, Washington.

China a Angola, contra 31.1 millares de millones de dólares importados.

Esto convierte a China en el mayor socio comercial de Angola, según el informe de 2012 del Observatorio de la Complejidad Económica. ${ }^{28}$ Del total de las exportaciones de Angola, $60.78 \%$ se destinan a China, país seguido por India, adonde se exporta $14.72 \%$ del total, y Sudáfrica, con $5.88 \%$ de represen-

${ }^{28}$ Simoes e Hidalgo, The Economic Complexity Observatory, op. cit. 
CuAdro 3. Balanza comercial entre China y Angola, 1992-2014 (dólares corrientes)

\begin{tabular}{lccr}
\hline & $\begin{array}{c}\text { Exportaciones } \\
\text { de China } \\
\text { con destino } \\
\text { a Angola }\end{array}$ & $\begin{array}{c}\text { Importaciones } \\
\text { de China con } \\
\text { origen en } \\
\text { Angola }\end{array}$ & \\
Año & & Saldo \\
\hline 1992 & 8472850 & 29409207 & -20936357 \\
1993 & 11206948 & 180710462 & -169503514 \\
1994 & 12482005 & 47984324 & 35502319 \\
1995 & 21159336 & 136907302 & -115747966 \\
1996 & 28533705 & 243751143 & -215217438 \\
1997 & 29128511 & 603496146 & -574367635 \\
1998 & 36653028 & 153697712 & -117004684 \\
1999 & 16363697 & 355651156 & -339287459 \\
2000 & 33735509 & 1842692967 & -1808957458 \\
2001 & 45721834 & 721828095 & -676106261 \\
2002 & 61310901 & 1087049343 & -1025738442 \\
2003 & 145791215 & 2205934880 & -2060143665 \\
2004 & 193517905 & 4717339146 & -4523821241 \\
2005 & 372793946 & 6581828714 & -6209034768 \\
2006 & 894185633 & 1093329510 & -10039109474 \\
2007 & 1234518651 & 12888664603 & -11654145952 \\
2008 & 2942469756 & 22382523829 & -19440054073 \\
2009 & 2385960008 & 14675830702 & -12289870694 \\
2010 & 2003872576 & 22815049454 & -20811176878 \\
2011 & 2784153366 & 24922180492 & -22138027126 \\
2012 & 4039171270 & 33561896917 & -29522725647 \\
2013 & 3964058933 & 31972669347 & -28008610414 \\
2014 & 5975306809 & 31106015046 & -25130708237 \\
\hline & & & \\
\hline & & &
\end{tabular}

Fuente: Elaboración de los autores con datos de United Nations, U.N. Comtrade International Trade Statistics Database, Washington.

tatividad. Estados Unidos, por ejemplo, ya no está entre los 10 mayores destinos de las exportaciones de Angola. En 1995, 72.21\% de estas exportaciones tenían como destino Estados Unidos; en 2000, sólo cinco años después, 52.34\% del total se dirigía a Estados Unidos y $25.69 \%$ había sido destinado a China. En 2004, la diferencia entre los dos gigantes se redujo a $40.29 \%$ y $39.91 \%$ respectivamente. Y en 2010, China superó 
a Estados Unidos con $44.96 \%$ del total exportado de Angola contra sólo $23.97 \%$ de Estados Unidos.

El movimiento opuesto sucede con las importaciones que tienen otros protagonistas, como Portugal y Francia. En 1995, del total importado por Angola, 27.79\% procedía de Francia, $22.98 \%$ de Portugal, $9.84 \%$ de Estados Unidos y $1.45 \%$ de China; en 2000, estas cifras fueron, respectivamente, de 6.13, $18.38,11.86$ y 1.82 por ciento.

En 2004, los países europeos pierden protagonismo en Angola. El papel principal pasa a los países asiáticos, entre los que destaca Corea del Sur, del cual Angola obtuvo $27.76 \%$ de sus importaciones de ese año. Entre los socios asiáticos, China ocupó el tercer lugar con 2.96\% de las importaciones de Angola, y de los países europeos, Portugal lideraba con $12.53 \%$, seguido de Francia, con $4.15 \%$. Estados Unidos ascendió a $8.91 \%$ de las importaciones totales en 2004.

En 2010 el escenario cambia nuevamente: Portugal, 16.44\%; Francia, 5.35\%; China 13\%; Estados Unidos, 7.36\%; Sudáfrica, $8.13 \%$, e India, $3.73 \%$; en 2012, las principales importaciones de Angola fueron de China, con $20.56 \%$, y Portugal, con $20.27 \%$. Sudáfrica fue responsable de $8.66 \%$ de todo el volumen importado, y Estados Unidos de solamente 4.94 por ciento.

En este movimiento, China se constituye no como uno de los socios comerciales más importantes de Angola, sino como el principal. Es este vínculo el tema de la siguiente sección.

\section{El papel del petróleo en las relaciones entre China y Angola}

Según datos de 2014 de la U.S. Energy Information Administration, Angola es el segundo mayor productor de petróleo de África subsahariana, sólo superado por Nigeria. La actividad petrolera representa la mayor proporción de los ingresos del gobierno y casi la totalidad de las exportaciones angoleñas. Su participación en la producción mundial de petróleo es tan significativa que Angola se convirtió en miembro de la Organización de Países Exportadores de Petróleo en 2007. Según la U.S. Energy Information Administration, en 2013 la produc- 
ción promedio de petróleo y otros derivados líquidos en Angola fue de aproximadamente 1.8 millones de barriles por día, de los cuales 1.7 millones fueron de petróleo crudo. ${ }^{29}$

Para controlar la producción y la explotación de petróleo en Angola se estableció, en 1976, la Sociedad Nacional de Combustibles de Angola (Sonangol), que es accionista de la mayoría de las empresas que explotan petróleo en el país, además de contar con 17 filiales que operan en la industria del petróleo y del gas natural. Sin embargo, en Angola también están presentes muchas empresas extranjeras de explotación de petróleo y gas, principalmente de Estados Unidos, Europa y, más recientemente, de China.

A partir de 2002 - con el inicio de la explotación de yacimientos de petróleo en aguas profundas, descubiertos en la década de 1990- y hasta 2008, la producción de petróleo en Angola creció anualmente, en promedio, 15\%, lo que lo hizo aún más dependiente de este producto para su "supervivencia" como nuevo Estado independiente.

Es decir, el reciente crecimiento del PIB de Angola se atribuye al desarrollo de la explotación del petróleo y al producto de sus exportaciones. Como se observa en el cuadro 4, hay cierta relación positiva entre las dos variables, sobre todo en la década de 2000, pues el petróleo llegó a 92.8\% de las exportaciones de Angola en el periodo 2000-2014.

El desarrollo de dichas exportaciones puede deberse a varios factores: el crecimiento económico mundial; el aumento de la demanda internacional de recursos naturales, incluido el petróleo; la devaluación del dólar (entre 2003 y 2012, principalmente), y también el "efecto China".

Como se observa en el cuadro 3, el flujo de las exportaciones de Angola a China es mucho mayor que el flujo inverso; es decir, las importaciones chinas de Angola son más importantes en volumen y valores, aunque la composición es, casi en su totalidad, de petróleo crudo, como se muestra en el cuadro 5.

Por lo tanto, el comercio de petróleo entre China y Angola hace de este último el principal socio de China en el África subsahariana. Esta relación refleja los cambios en el escenario

${ }^{29}$ U.S. Energy Information Administration, Countries, Washington. 
Cuadro 4. Exportaciones totales y de petróleo de Angola, 1996-2014 (en millares de millones de dólares)

\begin{tabular}{cccc}
\hline & & & $\begin{array}{c}\text { Participación } \\
\text { del petróleo en } \\
\text { las exportaciones } \\
\text { totales }\end{array}$ \\
Año & $\begin{array}{c}\text { Exportaciones } \\
\text { totales }\end{array}$ & $\begin{array}{c}\text { Exportaciones } \\
\text { de } \\
\text { petróleo }\end{array}$ & $\begin{array}{c}\text { (\%) } \\
1996\end{array}$ \\
1997 & 4.67 & 4.22 & 90.34 \\
1998 & 4.70 & 4.19 & 89.13 \\
1999 & 3.83 & 2.95 & 77.16 \\
2000 & 4.79 & 3.76 & 78.52 \\
2001 & 8.19 & 7.89 & 96.41 \\
2002 & 6.75 & 5.97 & 88.50 \\
2003 & 7.94 & 7.20 & 90.65 \\
2004 & 9.32 & 8.80 & 94.45 \\
2005 & 12.77 & 12.33 & 96.58 \\
2006 & 22.09 & 20.94 & 94.80 \\
2007 & 32.05 & 30.67 & 95.70 \\
2008 & 41.69 & 38.34 & 91.96 \\
2009 & 67.74 & 65.40 & 96.55 \\
2010 & 39.92 & 37.65 & 94.32 \\
2011 & 53.45 & 39.40 & 73.72 \\
2012 & 66.23 & 63.15 & 95.35 \\
2013 & 74.42 & 70.23 & 94.38 \\
2014 & 71.57 & 67.29 & 94.01 \\
\hline & 64.69 & 61.28 & 94.74 \\
\hline & & & \\
\hline
\end{tabular}

Fuente: Elaboración de los autores con datos de United Nations, U.N. Comtrade International Trade Statistics Database, Washington.

internacional en términos de consumo de energía y su producción, responsables de la relación actual de los dos países.

No puede, sin embargo, sobrestimarse la relación comercial que se formó alrededor del petróleo. El papel de China en Angola va más allá: es pieza clave en el proceso de restauración del país africano tras su terrible conflicto interno, que duró más de 20 años. 
CuAdro 5. Composición de las importaciones de China con origen en Angola, 2000-2014 (en millares de millones de dólares)

\begin{tabular}{lccc}
\hline Año & $\begin{array}{c}\text { Importaciones } \\
\text { depetróleo }\end{array}$ & $\begin{array}{c}\text { Importaciones } \\
\text { totales }\end{array}$ & Petróleo/total \\
\hline 2000 & 1.84 & 1.84 & 100 \\
2001 & 0.72 & 0.72 & 100 \\
2002 & 1.09 & 1.09 & 100 \\
2003 & 2.21 & 2.21 & 100 \\
2004 & 4.72 & 4.72 & 100 \\
2005 & 6.58 & 6.58 & 100 \\
2006 & 10.93 & 10.93 & 100 \\
2007 & 12.88 & 12.89 & 99.9 \\
2008 & 22.36 & 22.38 & 99.9 \\
2009 & 14.6 & 14.68 & 99.5 \\
2010 & 22.75 & 22.82 & 99.7 \\
2011 & 24.81 & 24.92 & 99.6 \\
2012 & 33.37 & 33.56 & 99.4 \\
2013 & 31.81 & 31.97 & 99.5 \\
2014 & 30.89 & 31.11 & 99.3 \\
\hline
\end{tabular}

Fuente: Elaboración de los autores con datos de United Nations, U.N. Comtrade International Trade Statistics Database, Washington.

\section{La importancia de China para Angola}

El crecimiento y la consiguiente necesidad de recursos llevaron a China, a principios de este siglo, a ampliar sus inversiones e instalarse más allá de sus fronteras, a fin de garantizar el suministro de recursos naturales y materias primas esenciales para su operación.

Como resultado de este movimiento, las empresas chinas están en el grupo de multinacionales que más se expanden e invierten en los mercados extranjeros. El principal destino de sus inversiones directas se encuentra en Asia; sin embargo, actualmente se inclina por los mercados de países en desarrollo, como América Latina y África. Y entre los países en desarrollo destacan los africanos, pues el crecimiento de la inversión directa anual ha sido muy significativo. 


\section{CuAdro 6. Flujo de inversiones directas de China en África}

\begin{tabular}{|c|c|c|c|c|c|c|c|}
\hline $\begin{array}{l}\text { Flujo de inversiones } \\
\text { (en millones } \\
\text { de dólares) }\end{array}$ & 2003 & 2005 & 2007 & 2009 & 2011 & 2012 & $\begin{array}{l}\text { Crecimiento } \\
\text { de } 2010 \\
\text { a } 2012\end{array}$ \\
\hline Países en desarrollo & 2605 & 11216 & 22891 & 48780 & 60034 & 70017 & $23 \%$ \\
\hline $\begin{array}{l}\text { África } \\
\text { Participación }\end{array}$ & $\begin{array}{r}75 \\
3 \%\end{array}$ & $\begin{array}{l}392 \\
3 \%\end{array}$ & $\begin{array}{r}1574 \\
7 \%\end{array}$ & $\begin{array}{r}1439 \\
3 \%\end{array}$ & $\begin{array}{r}3173 \\
5 \%\end{array}$ & $\begin{array}{r}2517 \\
4 \%\end{array}$ & $19 \%$ \\
\hline $\begin{array}{l}\text { Angola } \\
\text { Participación }\end{array}$ & & & $\begin{array}{r}41 \\
3 \%\end{array}$ & $\begin{array}{r}8 \\
1 \%\end{array}$ & $\begin{array}{r}73 \\
2 \%\end{array}$ & $\begin{array}{r}392 \\
16 \%\end{array}$ & $288 \%$ \\
\hline $\begin{array}{l}\text { Rep Dem. Congo } \\
\text { Participación }\end{array}$ & & $\begin{array}{r}5 \\
1 \%\end{array}$ & $\begin{array}{r}57 \\
4 \%\end{array}$ & $\begin{array}{r}227 \\
16 \%\end{array}$ & $\begin{array}{r}75 \\
2 \%\end{array}$ & $\begin{array}{r}344 \\
14 \%\end{array}$ & $46 \%$ \\
\hline $\begin{array}{l}\text { Mozambique } \\
\text { Participación }\end{array}$ & & $\begin{array}{r}3 \\
1 \%\end{array}$ & $\begin{array}{r}10 \\
1 \%\end{array}$ & $\begin{array}{r}16 \\
1 \%\end{array}$ & $\begin{array}{r}20 \\
1 \%\end{array}$ & $\begin{array}{r}231 \\
9 \%\end{array}$ & \\
\hline $\begin{array}{l}\text { Nigeria } \\
\text { Participación }\end{array}$ & $\begin{array}{r}24 \\
32 \%\end{array}$ & $\begin{array}{r}53 \\
14 \%\end{array}$ & $\begin{array}{r}390 \\
25 \%\end{array}$ & $\begin{array}{r}172 \\
12 \%\end{array}$ & $\begin{array}{l}197 \\
6 \%\end{array}$ & $\begin{array}{r}333 \\
13 \%\end{array}$ & $80 \%$ \\
\hline $\begin{array}{l}\text { Zambia } \\
\text { Participación }\end{array}$ & $\begin{array}{r}6 \\
8 \%\end{array}$ & $\begin{array}{r}10 \\
3 \%\end{array}$ & $\begin{array}{l}119 \\
8 \%\end{array}$ & $\begin{array}{l}112 \\
8 \%\end{array}$ & $\begin{array}{r}292 \\
9 \%\end{array}$ & $\begin{array}{r}292 \\
12 \%\end{array}$ & $289 \%$ \\
\hline $\begin{array}{l}\text { Zimbabue } \\
\text { Participación }\end{array}$ & & $\begin{array}{r}1 \\
0 \%\end{array}$ & $\begin{array}{r}13 \\
1 \%\end{array}$ & $\begin{array}{r}11 \\
1 \%\end{array}$ & $\begin{array}{r}440 \\
14 \%\end{array}$ & $\begin{array}{r}287 \\
11 \%\end{array}$ & $744 \%$ \\
\hline
\end{tabular}

Fuente: Elaboración de los autores con datos de UNCTAD, "China: FDI flows abroad, by geographical destination (Table 2)", Ginebra.

En el cuadro 6 se ve que, entre los países en desarrollo, África todavía representa una pequeña parte de la inversión directa china, pero el crecimiento en sus principales destinos - Angola, República Democrática del Congo, Mozambique, Nigeria, Zambia y Zimbabue- fue muy importante en los últimos años. El caso más significativo es el de Zimbabue, que si bien en 2010 recibió sólo 34 millones de dólares en inversión directa, en 2011 obtuvo 440 millones de dólares, y en 2012, 287 millones de dólares, con un aumento de 744\% en estos dos años.

Las inversiones chinas en los países africanos son cada vez más comunes debido al interés de sus multinacionales por ciertos recursos estratégicos, especialmente el petróleo. Según Amaury Porto de Oliveira: 
Es sobre todo en África (Sudán, Angola, Argelia y otros) donde las tres más grandes empresas petroleras de China: CNPC (China National Petroleum Corporation); CNOOC (China National Offshore Oil Corporation); y Sinopec (China Petroleum and Chemical Corporation) han tenido éxito. Decenas de acuerdos comerciales y de inversión fueron firmados sobre la base del trabajo de estas empresas, y en 2005 China importó 38 millones de toneladas de petróleo de África, 30\% de todo el petróleo importado en el país. ${ }^{30}$

Como contraparte, el gobierno chino alienta la instalación de empresas chinas en el sector de la construcción, sobre todo con el fin de trabajar en la reconstrucción de la infraestructura de los países africanos.

El caso de Angola no es diferente: la presencia china tiene las mismas características; es decir, busca asegurar que pueda proporcionar el petróleo necesario a China, y continúe como el mayor exportador de materias primas del África subsahariana al país asiático. Además, fomenta la instalación de sus empresas en ese país. China ofrece muchos beneficios a Angola. En palabras de Stephanie Hanson:

Para Angola, que exportó cerca de 465000 barriles de petróleo por día a China en los primeros seis meses de 2007, Beijing ha planeado un importante papel en la producción futura de petróleo cuando, en 2004, contribuyó con un paquete de 2000 millones de dólares de préstamos para el país, que incluyen fondos para las empresas chinas para construir ferrocarriles, escuelas, carreteras, hospitales, puentes y oficinas; establecer una red de fibra óptica, y capacitar a los trabajadores de telecomunicaciones de Angola. ${ }^{31}$

Este "paquete de crédito" de 2000 millones de dólares es un préstamo del Eximbank de China a Angola, que exige a cambio el suministro de petróleo; en inglés se denomina "oil backed loan”. Este préstamo se otorga al gobierno de Angola, pero, sobre todo, a las empresas chinas en Angola cuya finalidad es la reconstrucción del país.

${ }^{30}$ Amaury Porto de Oliveira, "A política africana da China", en África-Conferência Nacional de Politica Externa e Política Internacional-II CNPEPI: o Brasil no mundo que vem aí, Brasilia, Fundação Alexandre de Gusmão, 2008, p. 27.

${ }^{31}$ Stephanie Hanson, China, Africa, and Oil, Washington, Council on Foreign Relations, junio de 2008, p. 2. 
Según Alex Vines, ${ }^{32}$ las obras más importantes que ya han comenzado a realizarse son el ferrocarril de Benguela que une el puerto de Lobito, la refinería de Lobito, el nuevo aeropuerto de Luanda, otros ferrocarriles y la construcción de edificios para el gobierno. Sin embargo, la línea de crédito incluye muchos otros proyectos, divididos en dos etapas. ${ }^{33}$

En la primera fase, en 2004 , había 50 proyectos en todo el país, por un valor de 1.1 millares de millones de dólares. Los principales eran la rehabilitación de 371 kilómetros de carretera entre Luanda y Uige; en el área de salud, la rehabilitación y ampliación de hospitales y centros de salud; en educación, la rehabilitación de escuelas secundarias y politécnicas; en el sector de agricultura, la adquisición de maquinaria y rehabilitación de sistemas de riego en Luena, Caxito, Gandjelas y Waco Kungo.

En la segunda fase, en 2007, se firmaron más de 17 contratos que incluyeron más de 52 proyectos. El objetivo del segundo ciclo era completar proyectos no terminados en la primera fase, además de los previstos para la segunda. Aunque permanecían como prioridad los proyectos para educación, la inversión debía dirigirse también al sector de la pesca y las telecomunicaciones.

Según Renato Aguilar y Andrea Goldstein, ${ }^{34}$ estas inversiones tan necesarias para la recuperación de Angola habían sido negadas por las instituciones financieras internacionales después de 2002, ya que el país no cumplía con los requisitos para recibir apoyo financiero. En la misma línea, otros dos autores agregan:

Las relaciones entre las instituciones financieras internacionales y Angola han sido precarias durante años. Los episodios recurrentes de la hiperinflación y la estabilización impidieron cualquier acuerdo duradero con el FMI. Las relaciones con el Banco Mundial también se limitaron a los proyectos de emergencia y la asistencia humanitaria debido a la falta de un marco acordado con el FMI. Al final de la guerra, en 2002, el FMI y muchos inversores occidentales querían negociar un "staff-

${ }^{32}$ Alex Vines, “China in Africa: A Mixed Blessing?”, Current History, vol. 106, mayo de 2007, pp. 213-219.

${ }^{33}$ Campos y Vines, Angola and China, op. cit., p. 23.

${ }^{34}$ Renato Aguilar y Andrea Goldstein, "The Chinisation of Africa: The Case of Angola”, The World Economy, vol. 32, núm. 11, 2009, pp. 1445 y 1558. 
monitored program" (SMP) que mostrara un buen rendimiento durante tres trimestres antes de ser elegible para recibir ayuda financiera. Un SMP daría credibilidad a la política económica de Angola y allanaría el camino a una conferencia de donantes a fin de recaudar fondos para la reconstrucción del país. Sin embargo, el gobierno de Angola no consideraba convenientes las condiciones del FMI y, después de varias rondas de consultas, anunció que dejaría de intentar llegar a un acuerdo con el FM. ${ }^{35}$

Los préstamos de China sólo exigían dos condiciones: suministro de petróleo y no reconocer a Taiwan. Es decir, a diferencia de los préstamos de organismos internacionales, como el Fondo Monetario Internacional o el Banco Mundial, China no exigía a Angola y otros países que recibían sus préstamos que cumplieran con las premisas del Consenso de Washington, sólo les imponía la condición de reconocer "Una sola China", y desconocer a Taiwan.

Por otra parte, a las élites y al gobierno de Angola, que según Ian Taylor se ajustan a la pauta de los regímenes africanos opresivos y dictatoriales, les convenía la postura china de no injerencia en los asuntos internos del país. Además, las condiciones de pago de los préstamos chinos son más flexibles:

Debido a la mala gobernanza de Luanda, el FMI estaba decidido a incluir medidas de transparencia para combatir la corrupción y mejorar la gestión económica; sin embargo, como el FMI había presionado para un acuerdo, el gobierno de Angola decidió repentinamente terminar con las negociaciones. La razón de esto fue que Luanda había recibido una contrapropuesta de un préstamo de 2000 millones de dólares de la agencia de crédito a la exportación de China, el Eximbank. El acuerdo fue acompañado de una propuesta de pago a una tasa de interés de $1.5 \%$ con plazo de 17 años, y fue condicionado a un contrato de suministro de 10000 barriles de crudo al día inicialmente, que aumentaría a 40000 barriles por día, y también a la adjudicación de las obras importantes. ${ }^{36}$

De hecho, para el gobierno de Angola se hace más atractivo mantener relaciones comerciales y diplomáticas con China. Las condiciones impuestas son más flexibles que las de las instituciones de Bretton Woods, y las ganancias son satisfactorias para ambas partes.

${ }^{35}$ Campos y Vines, Angola and China, op. cit., p. 18.

${ }^{36}$ Ian Taylor, "China's Oil Diplomacy in Africa", International Affairs, vol. 82, núm. 5, 2006, p. 947. 
El resultado hasta el momento ha sido positivo desde un punto de vista económico. El crecimiento económico de China y el suministro de petróleo que demanda han promovido el crecimiento económico sin precedentes en Angola. Como hemos visto, desde la década de 2000 su PIB mostró variaciones muy satisfactorias, menos de 20000 millones de dólares en 2000 a 160000 millones de dólares en 2012.

Por otro lado, hay que apuntar que este clima económico favorable no debe sobrestimarse. El continente africano en su conjunto fue incorporado a la economía mundial capitalista como zona periférica, ${ }^{37} \mathrm{y}$ desde entonces ésta ha sido la condición estructural, sistémica, de los países de la región. Como señala Giovanni Arrighi, ${ }^{38}$ hay estabilidad en el posicionamiento de los Estados en la economía capitalista: las posiciones centrales, semiperiféricas y periféricas se mantienen por largo tiempo. Las situaciones de ascenso, como Japón y Corea del Sur, son realmente excepcionales.

Los Estados periféricos son aquellos que producen y reproducen en sus territorios las actividades económicas consideradas periféricas en determinado momento histórico, y que no controlan las ganancias de estas actividades, las cuales son destinadas a los países centrales. ${ }^{39}$ Giovanni Arrighi también argumenta que la industrialización fue un mecanismo que creó la "ilusión de desarrollo", porque las periferias del mundo promovieron la industrialización en sus dominios después de la segunda mitad del siglo xx, pero no alcanzaron el nivel de bienestar de los países centrales. En otras palabras, se produjo el fenómeno de la "convergencia en la industrialización", mientras que se mantuvo la "divergencia en los ingresos". La periferia se industrializó, pero no se desarrolló.

${ }^{37}$ Immanuel Wallerstein, El moderno sistema mundial, México, Siglo XXI, 2011, pp. $179-190$.

${ }^{38}$ Arrighi, $A$ ilusão do desenvolvimento, op. cit., pp. 182-186.

${ }^{39}$ Giovanni Arrighi también argumenta que los Estados del centro controlan actividades económicas innovadoras y los semiperiféricos tienen, en sus territorios, una mezcla de actividades periféricas y centrales. China es una potencia global, pero si se considera el criterio de la renta de su población aún es un Estado semiperiférico. Sin embargo, desde la década de 1980, China concentra en su territorio actividades periféricas (textiles, por ejemplo) y ha cambiado poco a poco su estructura productiva para enfocarse en el desarrollo de actividades con más valor agregado, como bienes de alto contenido tecnológico. 
Cuadro 7. PIB per cápita de Angola, África y China en relación con Estados Unidos

$(\mathrm{EUA}=100)$

\begin{tabular}{lrrl}
\hline Año & China & Angola & África \\
\hline 1950 & 4.69 & 11.00 & 9.30 \\
1955 & 5.29 & 10.54 & 8.95 \\
1960 & 5.84 & 11.06 & 9.31 \\
1965 & 5.23 & 11.89 & 8.80 \\
1970 & 5.18 & 11.76 & 8.88 \\
1975 & 5.35 & 6.59 & 8.57 \\
1980 & 5.71 & 5.18 & 8.15 \\
1985 & 7.33 & 3.76 & 6.97 \\
1990 & 8.06 & 3.74 & 6.14 \\
1995 & 11.62 & 2.56 & 5.46 \\
2000 & 11.92 & 2.57 & 5.26 \\
2005 & 18.08 & 3.36 & 5.62 \\
2010 & 26.34 & 5.25 & 6.67 \\
\hline
\end{tabular}

Fuente: Elaboración de los autores con datos de University of Groningen, The Maddison-Project, Groninga.

El cuadro 7, que compara el desarrollo del PIB per cápita de Angola y África con el de Estados Unidos entre 1950 y 2010, muestra cómo el resultado favorable de la década de 2000 simplemente coloca a Angola en la misma situación en la que estaba en 1980. Como ha destacado Ouriques, ${ }^{40}$ la mayoría de los países africanos, y especialmente los beneficiados por el alza de precios de los productos básicos de la década de 2000 , sólo han recuperado el terreno perdido durante la llamada "crisis africana" (1975-2000). ${ }^{41}$ En el caso de Angola, sus mayores vínculos económicos con China no fueron y no son suficientes para cambiar su posición periférica estructural en la economía capitalista mundial. En el capitalismo histórico, las

${ }^{40}$ Ouriques, “As relações econômicas entre China e África”, op. cit., p. 36.

${ }^{41} \mathrm{Un}$ análisis acerca de la naturaleza de la crisis africana, desde la perspectiva sistémica, lo elabora Giovanni Arrighi en "A crise africana: aspectos regionais e sistêmicos do mundo”, en Emir Sader (comp.), Contragolpes: seleção de artigos da New Left Review, San Pablo, Boitempo, 2006, pp. 31-60. 
posibilidades de desarrollo (en el sentido de equiparación con los patrones del nivel de vida de los países centrales) son limitadas y no son realizables para todos al mismo tiempo; en otras palabras, el desarrollo es geográficamente desigual, como lo reconoce el propio Banco Mundial. ${ }^{42}$ Así, en una perspectiva de más largo plazo, Angola tiene posibilidades limitadas de "ascensión” en el contexto de la economía-mundo capitalista, que es desigual y polarizadora.

\section{Consideraciones finales}

La presencia china en África tiene como principal característica la búsqueda de recursos naturales y materias primas necesarias para el mantenimiento de su desarrollo económico. Al ser China incapaz de producir los insumos que requiere para mantener su rápido crecimiento, su expansión industrial y su mercado interno, desde la década de 2000 ha fortalecido los lazos con sus proveedores e intensificado la importación de los bienes necesarios, provenientes, en su mayoría, de países en desarrollo, especialmente de los países africanos.

Las relaciones entre China y Angola son más significativas desde el punto de vista comercial y financiero mediante la inversión directa, que se dirige principalmente al sector petrolero y de la construcción. En el primero se enfoca, junto con Sonangol, en la explotación de petróleo. Y en el segundo, las empresas chinas son responsables de las inversiones fundamentales para la recuperación de la infraestructura del país.

De esta forma, se infiere que, hasta el momento, China ha funcionado como motor de crecimiento de Angola en los últimos años, así como de otros países de las periferias del capitalismo global (en África y América Latina), lo que no implica la pérdida de la predominancia occidental en la economía mundial, pero sí permite afirmar que el crecimiento experimentado por los países del Este de Asia, en particular de China, fue y es, en gran parte, responsable de la intensificación de las relacio-

\footnotetext{
${ }^{42}$ Banco Mundial, Informe sobre el desarrollo mundial: una nueva geografía económica, Washington, Banco Mundial, 2009, p. 5.
} 
nes sur-sur, y del crecimiento y desarrollo de las economías periféricas, las cuales no gozaban hasta entonces de los beneficios de la economía capitalista.

Por supuesto, el crecimiento del PIB de Angola y de su volumen de comercio en los últimos años no puede per se medir si hubo o no desarrollo socioeconómico en el país. Como ejemplos, la esperanza de vida en Angola sigue siendo de 51 años, muy inferior al promedio de los países en desarrollo, y la mortalidad infantil todavía alcanza 10\%. Como apunta Perla Olguín Vélez, ${ }^{43}$ la pobreza y la desigualdad aún son muy elevadas en el país.

Además, hay otras cuestiones que merecen ser puntualizadas y abordadas más profundamente para entender los beneficios reales de la presencia de China en Angola. Entre ellos:

a) La falta de diversificación económica en Angola: sus exportaciones dependen casi exclusivamente de los productos básicos; el PIB se compone en $80 \%$ de los ingresos de la economía del petróleo, y otros sectores son poco explotados en el país.

b) Los efectos negativos para los pequeños agricultores, uno de los sectores que menos se beneficia de cualquier crecimiento económico. Y la mayoría de la población angoleña vive de la agricultura familiar.

c) La mano de obra empleada en los trabajos de reconstrucción está, en su mayoría, compuesta por expatriados chinos. Así, no hay un aumento significativo en la tasa de empleo de los angoleños en el país.

d) Hay una gran concentración de la riqueza en Luanda: las pequeñas ciudades del interior tienen poco acceso a los recursos originados por la presencia china.

e) La falta de condiciones a la presencia y la inversión chinas sirve para mantener gobiernos altamente centralizados que no son sancionados por violaciones a los derechos humanos, desde los movimientos represivos hasta la falta de rendición de cuentas del Estado.

${ }^{43}$ Perla M. Olguín Vélez, "El compromiso de China con el desarrollo del Tercer Mundo: el caso Angola”, Estudios de Asia y África, vol. 46, núm. 3 (146), septiembrediciembre de 2011, pp. 600-605. 
f) La transferencia de conocimiento y tecnología: como la mayoría de las grandes empresas chinas se encuentran en Angola y emplean tecnología y mano de obra china, al parecer no hay transferencia de conocimientos y tecnología a Angola, lo que impide que desarrolle capacidades para sostener su crecimiento en caso de que, hipotéticamente, las relaciones con China se interrumpan.

En otras palabras, Angola sigue siendo un Estado periférico en la estructura de la economía-mundo capitalista. Su vinculación con China, hasta ahora, solamente ha significado una recuperación económica después de décadas de estancamiento y crisis, pero no es suficiente para transformar una situación estructural de subdesarrollo en una trayectoria de desarrollo y ascensión en el largo plazo en la economía-mundo capitalista. El país africano continúa, de esta manera, siendo proveedor de productos primarios, pero ahora para un nuevo "centro". Angola, en verdad, apenas ha cambiado de socio; si en el pasado eran Estados Unidos y Europa, ahora lo es China.

Dirección institucional de los autores:

Universidad Federal de Santa Catarina

Campus Universitário Reitor João David Ferreira Lima Trindades. $/ n$. 88040-900, Florianópolis, Santa Catarina, Brasil

\section{Bibliografía}

Aguilar, Renato y Andrea Goldstein, “The Chinisation of Africa: The Case of Angola", The World Economy, vol. 32, núm. 11, 2009, pp. 1543-1562.

Alden, Chris, "China in Africa", Survival: Global Politics and Strategy, vol. 47, núm. 3, 2005, pp. 147-164.

ARRIGHI, Giovanni, "A crise africana: aspectos regionais e sistêmicos do mundo”, en Emir Sader (comp.), Contragolpes: seleção de artigos da New Left Revierw, San Pablo, Boitempo, 2006, pp. 31-60.

Arrighi, Giovanni, $A$ ilusão do desenvolvimento, Petrópolis, Vozes, 1997.

Banco Mundial, Informe sobre el desarrollo mundial: una nueva geografía económica, Washington, Banco Mundial, 2009. 
Banco Mundial, World DataBank, Washington. [ $<$ databank.worldbank.org/indicator/NY.GDP.MKTP.CD > , consultado en marzo de 2015.]

Black, Clarissa, "Eventos relacionados ao superciclo de preços das commodities no Século XxI", Indicadores Econômicos, vol. 40, núm. 2, 2013, pp. 67-78.

British Petroleum, Statistical Review of World Energy 2013, Londres, 2013. [ <www.bp.com/statisticalreview >, consultado en mayo de 2015.]

Campos, Indira y Alex Vines, Angola and China: A Pragmatic Partnership, Londres, Center for Strategic \& International Studies, 2008.

CARmody, Padraig y Francis Owusu, "A expansão da China para a África: interesses e estratégias", en Rodrigo Pimentel Ferreira Leão, Eduardo Costa Pinto y Luciana Acioly (comps.), A China na nova configuração global: impactos políticos e econômicos, Brasilia, Instituto de Pesquisa Econômica Aplicada, 2011, pp. 235-267.

CoRkIn, Lucy, "China and Angola: Strategic Partnership or Marriage of Convenience?”, The Angola Brief, vol. 1, núm. 1, enero de 2011. EDOHO, Felix, "Globalization and Marginalization of Africa: Contextualization of China-Africa Relations", Africa Today, vol. 58, núm. 1, 2011, pp. 102-124.

Hanson, Stephanie, China, Africa, and Oil, Washington, Council on Foreign Relations, junio de 2008.

HASNAT, Baban, "The US and Chinese Foreign Direct Investment in Africa", China-USA Business Review, vol. 12, núm. 8, 2013, pp. 735-745.

Helbuing, Thomas, Valerie Mercer-Blackman y Kevin Cheng, "Commodities Boom: Riding a Wave", Finance and Development, vol. 45, núm. 1, marzo de 2008, pp. 10-15.

Jacobs, Sherelle, "Angola: Rise of a New African Superpower", African Business, núm. 387, junio de 2012, pp. 48-63.

Koblinski, Katarina, Chinese Investment in Africa: Checking the Facts and Figures, Briefing Paper 7, Association for International Affairs, julio de 2012.

Olguín Vélez, Perla M., "El compromiso de China con el desarrollo del Tercer Mundo: el caso Angola", Estudios de Asia y África, vol. 49, núm. 3 (146), septiembre-diciembre de 2011, pp. 589649.

Oliveira, Amaury Porto, “A política africana da China”, en ÁfricaConferência Nacional de Política Externa e Política InternacionalII CNPEPI: o Brasil no mundo que vem aí, Brasilia, Fundação Alexandre de Gusmão, 2008. 
OuRIQUes, Helton Ricardo, “As relações econômicas entre China e África: uma perspectiva sistêmica”, Carta Internacional, vol. 9, núm. 1, enero-junio de 2014, pp. 19-43.

Pautasso, Diego, "A economia política internacional da China para Angola e os caminhos da transação sistêmica", Século XXI, vol. 1, núm. 1, enero-diciembre de 2012, pp. 106-127.

Prates, Daniela M., "A alta recente dos preços das commodities", Revista de Economia e Política, vol. 27, núm. 3, 2007, pp. 323-344.

RENARD, Mary-Françoise, China's Trade and FDI in Africa, Working Paper 126, Túnez, African Development Bank Group, 2011.

Simoes, A. J. y C. A. Hidalgo, The Economic Complexity Observatory: An Analytical Tool for Understanding the Dynamics of Economic Development. Workshops at The Twenty-Fifth AAAI Conference on Artificial Intelligence, 2011. [ > http://atlas.media.mit.edu/en/ profile/country/ago/\#Exports/ > , consultado en mayo de 2015.]

TAYLOR, Ian, "China's Oil Diplomacy in Africa", International Affairs, vol. 82, núm. 5, 2006, pp. 937-959.

The China Analyst, "Hong Kong”, Hong Kong, The Beijing Axis, 2013.

UNCTAD, "China: FDI flows abroad, by geographical destination (Table 2)", Ginebra. [<www.unctad.org/Sections/dite fdistat/docs/ webdiaeia2014d3 CHN.pdf >, consultado en julio de 2014.]

United Nations, U.N. Comtrade International Trade Statistics Database, Washington. [ $<\mathrm{www}$.comtrade.un.org/data $>$, consultado en octubre de 2015.]

University of Groningen, The Maddison-Project, Groninga. [<www. ggdc.net/maddison/maddison-projetc/home.htm > , versión 2013, consultado en febrero de 2016.]

U.S. Energy Information Administration, Countries, Washington. $[<$ eia.gov/forecasts/steo/tables/?tableNumber $=7 \#>$, consultado en enero de 2015.]

VINES, Alex, "China in Africa: A Mixed Blessing?”, Current History, vol. 106, mayo de 2007, pp. 213-219.

WALLERSTEIN, Immanuel, Capitalismo histórico e civilização capitalista, San Pablo, Contraponto, 2001.

Wallerstein, Immanuel, El moderno sistema mundial, México, Siglo XXI, 2011.

World Bank, Angola-Oil, Broad-Based Growth, and Equity, Washington, World Bank, 2006. 